T. A. Pitterie

N. C. Paik

Westinghouse Advanced Reactors Division

Box 158

Madison, Pennsyluania

This report was prepared as an account of work sponsored by the United States Government. Neither the United States nor the United States Atomic Energy Commission, nor any of their employees, nor any of their contractors, subcontractors, or their employees, makes any warranty, express or implied, or assumes any legal lisbility or responsibility for the accuracy, completeness or usefulness of any information, apparatus, product or process disclosed, or represents that its use would not infringe privately owned rights.

\title{
Irvited Paper
}

For Presentation At

\section{Topica? Meeting}

New De velopments in Reactor Physics

ard Shielding Calculations

Ki amesha Lake, New York

September 12-15, 1972

* Work performed under AEC Contract AT(11-1)3045, Task 4B. 
Summary of Analyses of Plate vs. Pin Measurements

Emphasizing Reactivity and Sodium Void Effects

T. A. Pitterle

N. C. Paik

\section{Introduction}

This paper presents analyses of measurements performed in pin and plate environments of nearly identical composition in critical assemblies ZPPR-2 and ZPR-6-7 conducted by Argonne National Laboratory. Nearly all fast reactor critical assembly measurements, prior to the ZPPR-2 and ZPR-6-7 assemblies, have been made in plate environments using typically $1 / 16$ to $1 / 4$ inch wide plates to simulate fast reactor compositions. The plate environment of critical issemblies introduces heterogeneity effects which differ significantly fron that of an LMFBR which is comprised of fuel jins typically about $1 / 4$ inch in diameter. Consequently, the recent pin versus plate measurements are an important contribution to removing uncertainties in the extrapolation from plate critical measurements and analyses to the LMFBR pin environment. An improved capability for confident calculations of plate versus pin effects will significantly improve the applicability of future plate criticals toward reducing LMFBR physics design uncertainties.

The pin versus plate measurements in ZPPR-2 and ZPR-6-7 were performed by replacing small regions of the normal plate core with pin calandria containing 16 fuel rods $(0.410$ and 0.348 inch diameter clad ard mixed oxide fuel pellet diameters, respectively) across the approximately $2 \times 2$ inch cross sectional area. Figure 1 shows a cross section view of the ZPPR-2 assembly which outlines the central pin region (69 matrix drawers) and the radial pin sector. Initial pin versus plate measurements were performed in the central 69 drawers and the pin calandria were then rearranged into the radial pin sector for later measurements. Figure 1 also shows cross sections of the ZPPR-2 inner core zone p'ate arrangement and of the pin calandria. Assembly ZPR-6-7 was a large single zone assembly having the same plate arrangement and composition as the inner core zone of ZPPR-2. 
In ZPR-6-7, the pin sector was comprised of 25 drawers. Axially, the ZPPR-2 pin region included the ful1 36 inch core height and 6 inches into the axial biankets while the ZPR-6-7 pin region inciuded only the centrat 24 inches of the 60 inch core height.

The principal sources for differences in measurements or calculations are due to changes in heterogeneity affecting resonance self-shielding and the detailed fine neltron flux structure between fissile or fertile regions and the diluent (sodium, stainless steet, or iron) regions. An unresolved potential froblem is whether neutron leakage is affected differently in plate or pin environment. The flux and resonance heterogeneity ${ }^{2}$ effects are dominated by changes affecting Pu-239 and U-238 with contributions from other isotopes comparatively small although not completely negiigible. Heterogeneity effects lead to slightly softer neutron flux spectrum in the plate environment than in the pin or hypothetical truiy homogeneous environment. The effects on eigenvalues (criticality) and on sodium voiding are the most difficult to calculate as the net effects on these measurements are comprised of compensating positive and negative reactivity effects. Heterogeneity effects on other measurements such as the Doppler effect, central cavity reaction rate ratios, etc., are due primarily to affects on the gross flux spectra and are generally easier to calculate.

This paper presents detailed results of analyses by the present authors on the principal plate versus pin measurements includes reactivity (eigenvaiue), sodium voil, reaction rate ratio and Doppler (heated sample measurements) effects. Principal emphasis is placed on eigenvalue and sodium void ef:ects. Summary results of the authors are comsared with currently available calculations from ANL-Idaho (Refs. 1, 2, 3) and ANL-Chicago (Refs. 4, 5). As more details are currently available to the authors for the WARD calculations, the author's results are initially presented and then compared with the ANL calculations. 
Current uncertainties in delayed neutron yields lead to uncertainties

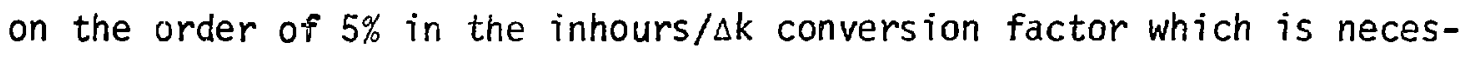
sary to compare experimer tally measured inhours with calculated $\Delta k$. The WARD results in this paper have been converted using 1000 inhours for $1 \% \Delta k$, as this value is comparable with previously published values for ZPPR-2. Howeler, a recent evaluation of delayed neutron yields by the present authors [7] leads to a calculated value of $953 \mathrm{ih} / \% \Delta \mathrm{k}$ for ZPPR-2. Consequently, the ratios of calculation/experiment given in this paper could be reduced by about. $5 \%$ for consistency with current evaluations of delayed neutron data. 
The reactivity effect on replacing pins by plates is an important consideration in comparirg calculated eigenvalues with experiment and corresponding estimates of eigenvalue uncertainties or adjustments for LMFBRs. Prior to the recent pin measurements, the only experimental data for testing reterogeneity estimates involved plate bunching experiments wherein reactivity effects of varying $p$ ?ate drawer arrangements were varied. The pin replacement experiments provide a more direct test of heterogeneity effects even though the experimental pin cells are somewhat more heterogeneous than an LMFBR fuel assembly

\section{Methods of Analysis}

Based on current calculational methods, the principal eigenvalue effects are expected to be resonance self-shielding and cell structure of the neutron flux which also lead to effects on the neutron spectrum. Methods used for the plate calculations involved separate resonance self-shielding for each heavy element in each plate of the assembiy. The WARD codes XSRES and WTDX (modifications of the 1DX [6] code) are used for resonance seif-shielding and one-dimensional diffusion theory spatial flux averaging of the cross sections. The methods for resonance seiff-shielding use resonance equivalence principles [7] for assymel.ric slab cells and cylindrical lattices. The cylindrical cell was based on the actual fuel pin diameter and matrix tube average volurie ratios and material densities. Comparison of resonance self-shield ng for the average cell with individual. self-shielding for corner, edge and center pins indicates no significant differences for the matrix averaged cross sections. However, the differences could be significant for individuai pin reaction rates. The calculations have been performed using 30 energy groups with modified ENDF/B-II data[8]. Comparative ca?culations [7] using this data and the ENDF/B-III data indicate the only significant differences between these data is that the ENDF/B-III data yield central sodium worth about $10 \%$ higher than the modified data. 
Spatial cell homogenization ${ }^{[7]}$ is perfomed using the one-dimersional transport theory code, ANISN [9], modified to perform the required cell flux weighting. Periodic boundary conditions are used for the plate cell calculations with input, plate independent values of $\mathrm{D}_{\mathrm{g}} \mathrm{g}^{2}$ (based on two-dimensional diffusion theory caiculations) for cell ieakage representation.

The cylindrical cell calculations for the pin studies a particularly sensitive to the cell boundary conditions. Based on themal reactor experience, "White" boundary conditions (isotropic reflection) are typically used for cylindrical cell calculations. However, the optical thickness of the moderation region in a thermal reactor is on the order of a neutron mean free path. Similarly, the fast reactor fuel pin is not as "black" to neutrons as a thermal reactor fuel pin. Using isotropic reflection for a fast reactor cell tends to force the angular flux in the cell to be almost isotropic everywhere in the cell. Some recent work by Choong $[10]$ indicates that, even for thermal reactor cells, the angular distribution for the returned neutrons should be slightly more peaked than the isotropic reflection assumption. Consequently, the white boundiry condition can lead to an underestimate of the flux variations in the cell. For this reason, parallel calculations were conducted using both white and reflective boundary conditions. A four regicn cell model was used based on fuel, cladding, sodium and calandria can plus matrix volume fractions. Reflective boundary conditions overs stimate the flux variations in the cell and the calculated fuel io cel! average flux ratios do not converge as the angular order is increased from S6 to 516 . The S6 caiculations yield a net flux heterogeneity reactivity effect similar to the plate cell while S16 effects are considerably greater than for the plate ce11. Cross sections from S6 calculations were used in ZPPR-2 analyses to provide results for an upper bound ( $\mathrm{S} 6$ reflective boundary conditions) and lower bound (white boundary conditions) on the fuel pin to cell average $f$ ? $u \lambda$ variations. Peaking factors usirig the white boundary conditions are independent of angular orders greater than S6. 
The ANL calculations used the $M C^{2}$ code $[11]$ for cross section averaging and resonance self-shielding with the CALHET code[12] for spatial flux weighting. CALHET uses collision probability methods with the collision probabilities tased on boundary conditions similar to the white condition.

\section{ZPPR-2 Plate vs. Pin Reactivity Calculations}

Table 1 presents results of ZPPR-2 plate versus pin heterogeneity calculations including perturbation theory isotopic contributions to the net effect. Also given are the corresponding components for the plate versus homogeneous calculations. Pin versus homogeneous effects can be obtained by subtracting the plate versus pin from the plate versus homogeneous effects.

The ZPPR-2 experimentally measurea plate versus pin reactivity effeci of $76.1 \pm 1.6$ inhours includes composition differences between the matched plate and pin calandria for which ANL has determined a correction of $8.43+6.65$ inhours based on experimental worth traverses. Then the composition corrected experimental value is $67.7 \pm 6.8$ inhours for the plate minus pin reactivity effect. The calculated composition correction is 16.2 inhours which included calculational errors for material worths. For ZPPR-2, the present ratilo of calculation/ experiment (C/E) for the central fissil: worth is 1.15 . About $5 \%$ of this $C / E$ value is believeld to be due to the use of $1000 \mathrm{ih} / \% \Delta \mathrm{k}$ as noted in the introduction. Based on an argument (a probable but unproven argument) that :he fissile centrai worth error is primarily due to errors in calcula:ed flux and adjoint distributions, about half of the remaining $10 \% \mathrm{C} / \mathrm{E}$ error could be assigned to the axial distributions and half to the radial distributions. Since the rod zone in ZPPR-2 has full axial core length, only the radial $5 \%$ integrated worth errors would apply to the rod zone. Acceptance of these arguments leads to an expected C/E of 1.1 for axially integrated worths using $1000 \mathrm{ih} / \% \mathrm{k}$. Table 1 includes in parentheses the composition contributions adjusted by multiplying the calculated isotopic contributions by $1.1 /$ (Central Worth $C / E$ ). The adjusted composition correction 
of 10.5 inhours is in acceptable agreenent with the experimentially based correction of $8.43+6.65$ inhours. It should be noted that the above assumptions on the centra? worth error have been made, to further speculation, while seeking a solution to the problem and are not technicaliy verified arguments.

The calculated plate versus pin reactivity effect is 137.8 inhours ( 88.4 in from cell flux $\in$ ffects plus 49.4 in from resonance self-shiel $1-$ ing effects) compared to the experimental value of $67.7+5.8$ ih. Using reflective cylindrical cell boundary conditions (expected to overestimate the flux heterogeneity), the calculated reactivity effect is on $7 y 38.5$ ih. The pin-homogenecus calculated reactivity effect is 87.0 in (224.8-137.8) and 186.3 in for white and reflective boundary conditions, respectively, compared to 224.8 in for the plate-homogeneous reactivity effect. The results using reflective boundary conditions can be expected to overestimate the flux heterogeneity for the pin $c \in 11$ and consequently underestimate the plate-pin flux contribution.

The discrepancy between caicuiation and measurement for the plate-pin reactivity effect could be due to an overestimate of the plate flux or resonance heterogeneity or corresponding underestimates for the pin geometry. The strong sensitivity to the cylindrical cell boundary condition indicates this problem to be a potentially significant source of error since the adequacy of white boundary conditions for a fast reactor cell does not aprear to be established. Sensitivity calculations performed for the $\mathrm{F}$ late cell by the present authors indicate variations of only about $15 \%$ based on acceptabie combinations of models, current methods and data. Even assuming a 15\% overestimate of the plate heterogeneity, the experimental plate-pin heterogeneity would be overestimated by $50 \%$ for the white boundary condition calculation. The cylindrical resonance self-shielding appears to be least sensitive to methods and data errors. It appears that unexpectedly large modifications of the plate heterogeneity calculations combined with an underestimate of the pin flux heterogeneity (when using white boundary conditions) would be required to obtain agreement between caiculation and experiment. Alternately, the calculations may not include a reactivity 
effect present experimentally but not included in the calculations. This possibility is further examined below. The present calculations have not included either flux or resonance self-shielding heterogeneity contributions from the axial blanket. Qualitatively, theso contributions are expected to be small arid likely to lead to a more positive plate-pin reactivity effect which would further increase the discrepancy with experiment. However, a calculation of the blanket contribution has not yet been performed.

Since plate versus pin reactivity measurements have been performed in both ZPPR-2 and ZPR-6-7, it is desirable to quantitatively check the relative consistency of the measurements. If the pin zones for either assembly introduce no large perturbations or unexpected reactivity effects, the measurements should be approximately the same when adjusted for differerices in pin region volumes, perturbation denominators (integrated fission worth) and peak to average worth ratio of the $\Delta k$ plate versus pin reactivity effect. The resulting ratio would then be given by:

$$
\begin{aligned}
& \frac{\Delta k(Z P P R-2)}{\Delta k(Z P R-6-7)} \simeq(\text { Pin volume ratio }) \div(\text { perturbation denominator ratio }) \\
& \div \text { (pin zone peak/average worth ratio) } \\
& \frac{\Delta k(Z P P R-2)}{\Delta k(Z P R-6-7)} \simeq\left(\frac{69 \times 36^{\prime \prime}}{25 \times 24^{\prime \prime}}\right) \div\left(\frac{161.3}{118.2}\right) \div\left(\frac{1.7}{1.2}\right) \\
& \frac{\Delta k(Z P P R-2)}{\Delta k(Z P R-6-7)}=2.1 \quad \text { estimated ratio }
\end{aligned}
$$

The first term in the above ratio corrects for the number and length of the pin calandria used in each experiment. The second term uses the experimental central Pu-239 worths as an indicator of the perturbation denominator ratio. The third term is based on calculated peak/average worth distributions for the plate versus pin reactivity change in ZPPR-2. Neglecting unexpected contributions to this ratio, the above ratio of 2.1 should be accurate to better than $25 \%$. The same ratio based un calculated central worths might be $10 \%$ lower die to the higher C/E ratio for the Pu-239 worth normally calculated for $\mathrm{ZPi}-6-7$. 
The experimentä plate versus pin reactivity effect is:

$$
\frac{\Delta k(Z P P R-2)}{\Delta k(Z P R-6-7)}=\frac{67.7 \pm \pm \frac{6.8}{52 . . \pm}}{3.4}=1.29 \pm 0.23
$$

The difference between the expected ratio of 2.1 and the experimental ratio of 1.29 may be an indication of an unexpected reactivity effect present in ZPPR-2 but not in ZPR-6-7. If the ZPPR-2 calculated value of 137.8 is adjusted by the expected 2.1 ratio, the resulting value of 65.6 in would be in much better agreement with the ZPR-6-7 measurements than for the ZPPR-2 measurement. Some possibie sources for the "apparent" inconsistency between the ZPPR-2 and ZPR-6-7 measurements could be: blanket effects in ZPPR-2 which would not occur in ZPR-6-7; local perturbation greater in ZPR-6-7; unknown experimental errors in one or both assemblies; and an unexpected reactivity effect more dominant in one of the two assemblies.

The possibility of an une xpected reactivity effect appears to be worth continued speculation in view of possible relation to the well known central worth discrepancy. A potential and conceivable explanation which could have significant effects on the use of critical experiments for design applications is the following: The plate criticals could have more leakage parallel to the plates due to streaming considerations than allowed for in present calculations and more leakage than in a rod environment. Then substitutions of pins with plates would lead to a less positive reactivily effect than currently calculated due to the enhanced leakage effect ' $n$ a plate environmert. This effect would be substantially larger in : :PPR-2 than ZPR-6-7 due to the greater axial flux gradients over the 1 in region of $Z P P R-2$ and thus reduce the expected reactivity ratio in the direction of the experimenta? ratio. Also the effect would tend to yie"d spatial flux distributions somewhat flatter in the core regions than currently calculated. This could lead to integrated fission worths (perturbation denominator) higher than presently calculated and tend to reduce the central worth discrepancy. 
This possible expianation appears to be worth more careful study due to the potential impact of such a problem. Colin Durston of WARD has suggested (private communication) the possibility that different diffusion coefficients (or transport cross sections) may be required parallel and transverse to the plates such as frequently used for thermal reactor applications. The current theory on this problem seem; to be quaitatively consistent with the above leakage speculation.

\section{Comparisons of Independent Plate versus P in Heterogeneity Calculations}

In addition to the present calculations, the plate versus pin reactivity effects have been calculated for ZPPR-2 by ANL.-Idaho[1] and for ZPR-6-7 by ANL-Chicago [4]. Results of these calcularions are given in Table II and include the results of total core plate heterogeneity (plate versus homogeneous) calculations. The ANL calculations of 82.6 ih for the 2PPR-2 plate vs. pin reactivity effect differs significantly from the present authors' result of 737.8 ih. About half of this difference may be attributable to the plate heterogeneity differences of $1.2 \% \Delta \mathrm{k}$ by ANL and $1.63 \% \Delta k$ by WARD. ANL's latest calculation of $1.6 \% \Delta k$ : for the ZPPR-2 plate heterogeneity is more consistent with the WARD vaiue. Recalculation of the plate vs. pin effect is currently underway at ANL and more detailed comparisons will be possibie when these calculations are completed.

The ANL-Chicago calculation of 50.9 in for ZPR-6-7 is in significantly better agreement with experiment than the ZPPR-2 calculations. This improved agreement with experiment for ZPR-6-7 calculations is consistent with expectations based on the previous discussions although the ANL C/E value for ZPPR-2 is notably better than for the WARD calculations. 
III. Reaction Rate Ratio and Doppler Effect Calculations

In Table III, comparisons of calculation and experiment are made for pin and plate environment. central reaction rate ratios, central worths and the ${ }^{238_{U}}$ Doppler effect. Calculations are included in the table using both white and reflective boundary conditions for the cylindrical cell calculations. The white boundary condition calculations yield a slightly harder neutron flux spectrum then obtained with reflective conditions. This result is indicated by the lower ${ }^{238} U$ Doppler effect, $10_{B}$ central worth and $\sigma_{\gamma}^{28 / \sigma_{f}^{49}}$ ratio obtained with the white boundary condition. Overall the calculated pin/plate ratios are in better agreement with experiment using the white boundary condition.

The ZPPR-2 experimental reaction rates given in the table are fission counter measurements while the $Z P R-6-7$ values are foil measurements averaged over the cell. Since the counter measurements tend to be an average measurement over the central drawer spectrum, they can be best compared with a calculacion using homogeneous cross sections as given for the non-asterisked calcuiations in Table III. The 7PR-6-7 cell-average measurements are best represented by the calculations using heterogeneous cell-homogenized cross sections as indicated with an asterisk in Table III. For both types of calculations, it appears that the pin/plate increase in the $\sigma_{f}^{28} / \sigma_{f}^{49}$ and $\sigma_{f}^{40} / \sigma_{f}^{49}$ ratios are underestimated while the $\sigma_{f}^{25} / \sigma_{f}^{49}$ and $\sigma_{\gamma}^{28} / \sigma_{f}^{49}$ ratios are well-calculated. For the plate core, the :odium voided reaction rate ratios are calculated with essentia $7 y$ the same accuracy as for the normal core.

The pin/plate ratio of 0.96 for the ${ }^{239} \mathrm{Pu}$ central worth is in good agreement with the experimental ratio. The pin/plate calculated ratio of 0.96 for the sodium central worth is in apparent disagreement with the experimental ratio of $1.16 \pm 0.10$. However, local geometry effects on these measurements appear to be large and the large region sodium void results of the next section of this paper are more amenable to calculation. 
For the ${ }^{238} \mathrm{U}$ Doppler effect, the pin/plate calculated ratio is a few percent higher than the experimental ratio al though within error bounds of the experimental ratics. The Doppler effect for the sodium voided core is underpredicted relative to experiment by about 12\% compared to about $3 \%$ for the normal core. This discrepancy would indicate an over prediction of the spectri] hardening upan sodium voiding. 


\section{Sodium Void Calculations}

The basic method used for sodium void calculations was first order perturbation theory. Crcss section differences between the sodium-in and sodium-out conditions were obtaired by performing separate resonance self-shielding and cell flux calculations. Checks on the accuracy of first order perturbation theory were performed using direct eigenvalue and "exact" (perturbed flux, unperturbed adjoint) perturbation theory calculations.

\section{Central Socium Void Calculations}

Tabie IV compares calculation and experiment for ZPPR-2 sodium voiding of the central regions up to 69 matrices. The first order perturbation theory calculations for the plate core indicate C/E values slightly greater than unity near the core center and slightly less than unity for the 69 matrix, 12 irch axial height (12 inches above and below core midplane) void region. A direct eigenvalue calculation for 18 inch (full core height) axial voiding gave a $\mathrm{C} / \mathrm{E}$ of 0.98 compared to 1.10 for perturbation theory. As noted later, this difference is consistent with an underestimation of the leakage component for sodium voiding. As the vcided region increases in size up to 69 matrices, the flux spectrum near the core center tends to become progressively harder leading to more pcsitive sodium voiding than predicted by perturbation theory. Direct eigenvalue calculations, which can account for the spectral hardenirg, predict more constant $C / E$ values with progressive voiding than perturbation theory.

The pin voiding calculations using white boundary conditions yield about $5 \%$ less positive void effects and lower pin/plate ratios than the calculations using reflective boundary conditions. The white boundary condition results tend to yield a somewhat flatter C/E value as the void size increases although no clear preference on boundary conditions can be made based on the C/E values. As the void height increases, the calculated pin/plate ratios increase by $7-10 \%$. 
However, the experimental accuracy for the central 12 and 18 inch void regions is insufficient to judge the accuracy of this increase.

Overall, the voiding for the central regions is calculated within about $5 \%$ accuracy for both the pin and plate environments with no unexpected difficulties in calculating either the pin or plate measurements .

\section{Components of Sodium Voiding}

Table $V$ presents the components of sodium voiding including the principal isotopic contributions from $\mathrm{Na},{ }^{238} \mathrm{U}$, and ${ }^{239} \mathrm{Pu}$. The contributions from ${ }^{238} \mathrm{U}$ and ${ }^{239} \mathrm{Pu}$ are given separately for cross section changes due to cell flux and resonance self-shielding differences between sodium-in and sodium-out.

From the table, it is seen that contributions from isotopes other than sodium contribute $1 E$ to $20 \%$ to the net (given by $\delta \Sigma^{\text {core }}$ ) void effect. As expected, the principal resonance self-shielding contribution occurs in ${ }^{238} \mathrm{U}$ which is a large positive effect while ${ }^{239} \mathrm{Pu}$ self-shielding contributes a small negative effect. The principal effects from tire cell flux variations for the plate core is a negative fission component dominated by ${ }^{239} \mathrm{Pu}$. Upon sodium voiding, the cell flux variations are reduced (the cell becomes more homogeneous). In the plate case, the largest effect is a reduction of the high energy flux peaking effects in the fissile plates so that the voided fission cross section is lower than the sodium-in cross section. Calculations of this flux effect for sodium voiding are sensitive to representation of axial leakage in the cell model so that the calculated flux terms are probably uncertain to about $25 \%$.

The dominant calculated differences between pin and plate voiding are due to a smaller ${ }^{238} \mathrm{U}$ resonance self-shielding contribution and a large reduction in the contributions from celi flux variations. Resonance self-shielding contributions from ${ }^{238_{U}}$ for the plate case are reduced 
by about $20 \%$ ( 0.85 in to 0.64 in for central 6 inch voiding) for the same for both pin and plate. The fiux effect contributions for the pin calculations are significantly different between white and reflective boundary conditions. Using white conditions, cell flux variations are small and flux effect contributions to sodium voiding are very small. With reflective conditions, the principle effect is a reduction in the low energy flux depressions in the fuel pin so that voided fission cross sections are higher than for sodium-in. This leads to a positive ${ }^{239} \mathrm{Pu}$ fission contribution to sodium voiding in contrast to the negative effect for plate voiding.

It is seen that the differences between pin and piate voided are almost completely dominated by differences in the heterogeneity contributions with cell flux effects being the largest difference. Moderation and leakage components are very similar for both pin and plate calculations although the white boundary condition pin calculations have $5 \%$ lower moderation and leakage components. The fact that the moderation components are similar for both pin and plate environment is largely due to a cancellation of effects. The adjoint spectrum for the plate case has a greater slope than the pin case, particularly at high energies. The positive void effect of this increased adjoint slope is compensated by a harder neutron spectrum for thie pin case.

The increase in the pin/plate ratio upon progressive axial sodium voiding is largely due tc the smaller leakage components in the pin environment compared to the plate environment. This effect may be due to differences in composition between the pin and plate environments rather than the trie plate versus pin effects.

The first order perturbation theory calculations given in this paper used the conventional assumption that:

$$
\delta D=\frac{-\delta \Sigma_{\operatorname{tr}}}{\Sigma_{t r} \Sigma_{\operatorname{tr}}^{1}}
$$


can be approximated by:

$$
\delta D=\frac{-\dot{-} \Sigma t r}{\Sigma_{t r}^{2}}
$$

where $\Sigma_{t r}^{l}$ is the perturbed transport cross section. For sodium voiding in ZPPR-2, the first, more exact expression yields leakage terms about $20 \%$ larger than the second approximation. The choice of terms is related to changes in the flux gradients upon sodium voiding. The present calculations indicate that agreement between first order perturbation theory and more exact calculations is improved if leakage terms calculated using the second expression are increased by $10 \%$. Table $V$ includes (in parenthesis) net calculations have the leakage term increased by 10\%. These adjusted results are in better agreement with the direct eigenvalue calculations for 18 inch axial voiding.

\section{Off-Center Plate Sodium loid Calculations}

At the present time, no significant analyses have been reported for measurements performed in tile pin sector of ZPPR-2, shown in Figure 1 . Both $R-Z$ and $X-Y$ geometry calculations of plate core sodium voiding for regions $A$ and $B$ of Figure $I$ have been parformed and the results are given in Table VI.

Based on the comparisons of $R-Z$ and $\mathbb{R}$ calculations, reference methods for the $X-Y$ calculation included: region dependent, group independent $B^{2}$ averaged over a 12-inch core height; axial leakage calculations basad on R-Z calculations; and a normalization correction of 0.87 for 12-irich axial voiding relative to 78 -inch core height. Sensitivity calculations were also made using group dependent $B^{2}$. Tha $X-Y$ calculations were performed using quarter-core symmetry with four mesh poirits per ZPPR-2 matrix position (drawer). The inner and outer core radi $i$ for the $R-Z$ calculation are 64.67 and $9 i .45 \mathrm{~cm}$., respectively, (based on equal areas of actual core zones) while the $X-Y$ radial distance; to the outer 
core region $B$ are 63.53 and $91.15 \mathrm{~cm}$., for the inner and outer edge, respectively. Due to the shorter radial distance to region $B$ in the actual $X-Y$ geometry, the flux levels in region $B$ will be slightly higher (particularly near the inner core) than obtained in the R-Z calculations.

Table VI compares calculation and experiment for the measure. nts reported in regions $A$ and $B$. For the $R-Z$ void calculations, the calculations for region $B$ are given as direct $R-Z$ results in $\mathrm{ih} / \mathrm{kg}$ and as a linear average over the five column subdivisions of region $B$ (indicated by footnote $e$ in the Tabie). The first procedure is representative of voiding a truly radial sector while the linear average better represents the experimental square region voiding. Components of the calculated worths including leakage terms in the radial and transverse directions from the $X-Y$ calculation are given in the Table. The fission, absorption and moderation terms from first order perturbation theory are about $3 \%$ higher in the $X-Y$ calculotion than the $R-Z$ calculation (footnote $e$ in the table). Radial leakage (sum of radial and transverse terms in $X-Y$ ) is about $3 \%$ lower in the $X-Y$ calculation. These differences are due primarily to the shift of $1.14 \mathrm{~cm}$. in the radial innerouter core boundary as noted above.

The measurements shown in Table VI for each column of region $B$ provides a qualitative cleck on the predictions for the spatial dependence of the void crefficient across the outer core zone. The results given in Tab ${ }^{\prime} \mathrm{V}$ VI shows that experiment predicts the void coefficient to becone negative for column 3 while calculation predicts a negative contribution starting in Column 2. This discrepancy is consistent $w^{\text {th }}$ th anderprediction of the positive void contributions (as a' so indicated for the 69 matrix central voidings) if one assumes that the leakage terms are accurately predicted. For example, if the moderation component is increased by $10 \%$, the $X-Y$ calculations agree with experiment to better than 
$5 \%$ for a 11 measurements regions $A$ and $B$ except Column 2 of $B$ which has $a$ large experimental uncertainty. However, the results from the central region voiding and the exact per:urbation theory results of Table VI indicate that the first order perturbat on theory leakage terms should be increased $5 y 10 \%$. Tests of diffusion theory against transport theory may be necessary to check the accuracy of diffusion theory for outer core zone voiding. For the regions $A$ and $B$ of $Z$ PPR-2, it appears that differences in the radial location of and $B$ of $2 P P R-2$, it appears that differences in the radial location of the voided regions between $R-Z$ and $X-Y$ geometry are more important than representation of the detailed geometry of the voided region (square in $X-Y$ versus ring in $R-Z$ ). However, for the $5 \times 5$ drawer voicing of region $B$ as contrasted to whole outer core voiding, the $R-Z$ exact perturbation theory results tend to overpredict the spectral hardening upon voiding (due to the necessity to void the whole outer core region in $R-Z$ geometry) compared to the $X-Y$ calculations. This trend is indicated by the differences between first order and exact perturbation theory of -0.09 and $-0.27 \mathrm{ih} / \mathrm{kg}$ for $R-Z$ and $X \cdot Y$ geometry, respectively.

The experimental values indicate that pin voiding for regions $A$ anc $B$ is less positive than plate voiding which is the opposite effect than found for the central void regions. Since the pin sectors is smaller than the central pin zone, local boundary effects could be more influential for the pin sector. Pin sector calculations should be performed and are particulariy sign:ficant in view of the relatively large $C / E$ value of 1.20 found for rogion $B$ compared to about 0.9 for region $A$.

In this study, comparison:: were made of $R-Z$ geometry void calculations with one-dimensional $R$ caiculations. These studies indicated that the use of group dependent bu:kiings (obtained from $R-Z$ geometry neutron flux solutions) gave excellent agreement for the neutron flux between the $R$ calculations and $R-\because$ valıes averaged over the height used to calculate the buckiings. However, the adjoint spectrum obtained using the group dependent bucklings gave poorer agreement with the $8-Z$ adjoint spectrum than obtained with group independent bucklings. These studies 
also indicated that the use of transverse $\delta D^{2}$ terms to calculate axial leakage for partial core height voiding is subject to very large inaccuracies. The buckling changes in core regions adjacent to the voided region (particularly axiclly adjacent regions) can contribute as much to the leakage term as the voided region itself. It would be difficult to incorporate these effects into $X-Y$ calculations.

The methods used for the $X-Y$ void calculations (combining $X-Y$ and $R-Z$ results) appears to provide a practical calculational scheme with adequate accuracy for voiding of irregular core geometries. Direct three-dimensional calculations would probably be required to obtain significantly improved accuracy. For full core height voiding, the use of axial leakage based on $\mathrm{DB}^{2}$ can be expected to provide accuracy comparable to an $R-Z$ leakage calculation although it might be necessary to include the $D B^{2}$ calculation in regions adjacent to the voided region for highly accurate calculations. The use of $X-Y$ methods rather than R-Z methods for sodium voiding can be expected to be of greater importance for cores containing heterogeneities such as control rods (a reactor design, ZPPR-Assembly 3, FFTF mockup critical assemblies). In these cases, the spatial variation of the void coefficient is significantiy greater than the nearly radial dependence in ZPPR-2. 


\section{Comparisons of ANL and WARD Calculations}

Table VII compares currently available analyses for pin and plate measurements in ZPPR-2 ard ZPR-6-7. As noted previously, the calculation/experiment ratios for the pin versus plate reactivity effect differ sianificantly between the ANL results for ZPPR-2 and ZPR-6-7. The largest difference, however, is the ZPPR-2 C.E value of 2.04 by the present authors compared to 1.22 by ANL. These experiments are currently being recalculated by ANL using the SDX code and ENDF/B-III data.

Preliminary ANL values for the total $p$ late heterogeneity (see Table II) indicate better agreement with the WRRD results than the previous values using $M C^{2}$ anci ENDF/B-I data.

Calculated pin/plate ratios for both ANL calculations and the WARD calculations are in good agreement for sodium voiding, $238 \mathrm{U}$ Doppler effect, central reaction rate ratios and the central $239 \mathrm{pu}$ worth. There is a consistent trend to underpredict the pin/plate reaction ratios for the threshhold fission of $238 \mathrm{U}$ and $240 \mathrm{Pu}$ al though the calculated ratios are close to the error bounds of the experimental data. The experimental pin/plate ratios for sodium voiding in ZPR-6-7 show equai or smaller pin voiding effects than plate voiding in contrast to the larger pin voiding effects in ZPPR-2. This experimental difference could be clue to the small pin region and laroe uncertainties for the ZPR-6-7 measurements. 


\section{Conciusions}

With the exception of the pin versus plate reactivity effects, calculations at boin ANL and WA 20 reproduce quite well the measured vaiues for pin/plate ratios including sodium void, Doppler effect, reaction rate ratio, and central $: 39 \mathrm{Pu}$ worth measurements. Differences in absolute values calculatıd for the latter measurements are largely due to differences in the cross section data used at ANL and WARD.

The trend to overpredict the pin versus plate reactivity effect in ZPPR-2 compared to ZPR-6-7, particulariy in the WARD calculations, indicates the possibility of a reactivity effect which is no: accounted for in the caiculations. The possibility of a reactivity effect due to greater neutron streaming parallel to the plates than occurs in the rod envircnment has been postulated in this paper. $C$. Durston of WARD has suggested an examination of methods for lising different diffu-. sion coefficients parallel and perpendicular to the plates in order to account for neutron diffusion assymetry. If additional studies should verify an assymetry effect, significant effects on eigenvalues, worth calculations and reaction rate distributions could be expected. Sodium void calculating could be particularly affected if directional leakage effects were important. The most immediate effect would be on design applications where bias iactors or uncertainties are established from plate critical experiments and applied to a rodded reactor where assymetry effects would be ccinsiderably smaller.

The strong sensitivity of cylindrical cell flux calculations to the cell boundary conditions indicates a need for further study on fast reactor applications. Although white boundary conditions are clearly superior to reflective conditions, it appears likely that the white conditions undarestimate the cell flux variations. The use of collision probabilities for a pin in a square lattice, such as those developed by Brissendon [13], could offer an improved solution for the critical experiment analyses while triangular pitch solutions might be required for fast reactor lattices. 


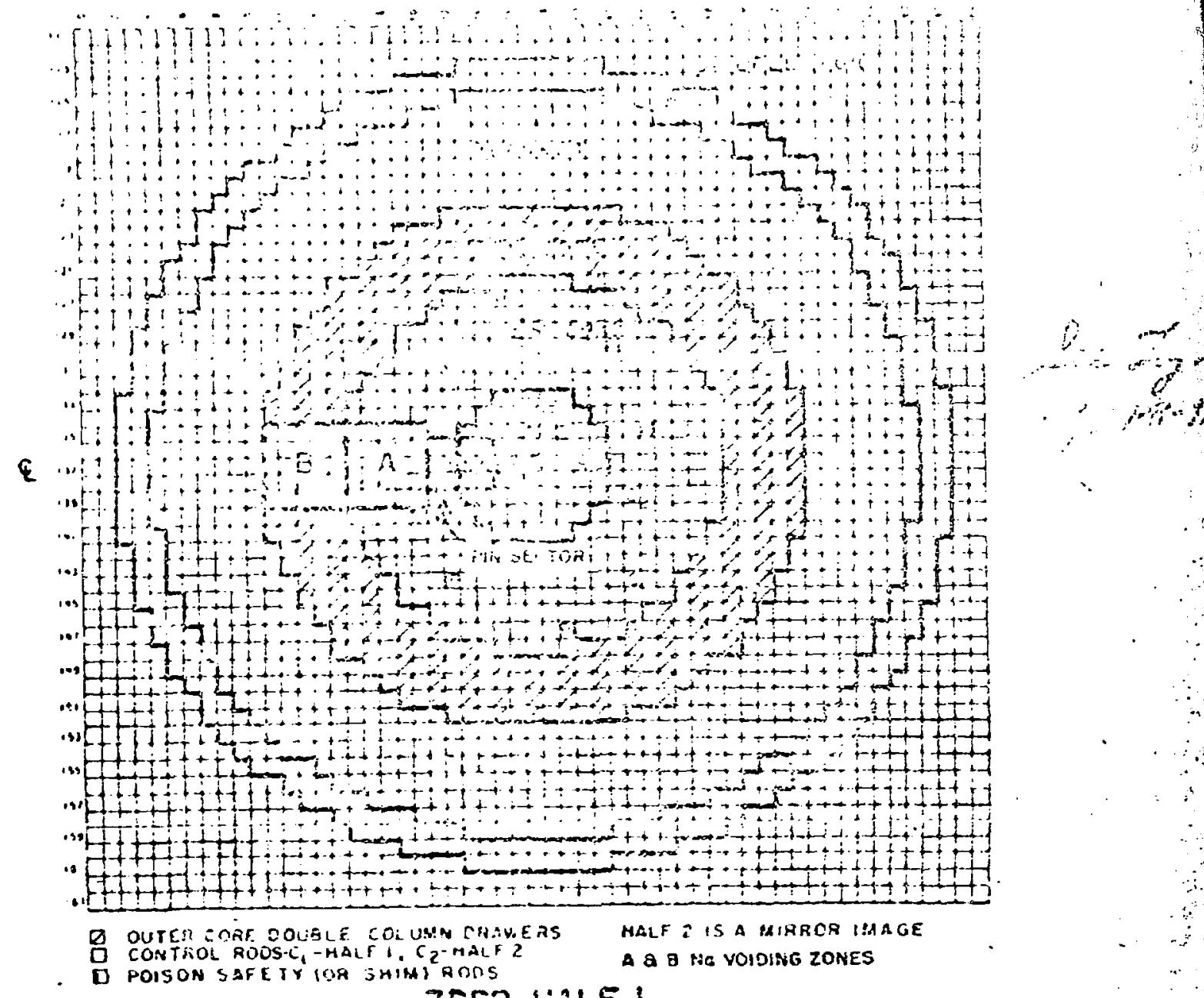

\section{ZFFR HALF I}

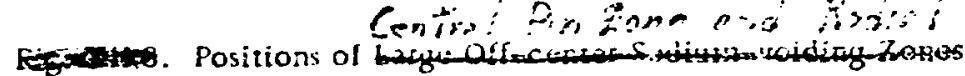

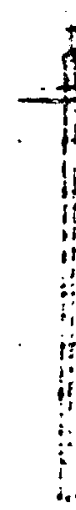


ZABLE I. CONTRIBUTIONS TO PIN AND PLATE HETEROGENEITY IN ZPPR-2 BY PERTURBATION THEORY

\begin{tabular}{|c|c|c|c|c|c|c|c|c|}
\hline \multirow[b]{2}{*}{ Isutope } & \multicolumn{3}{|c|}{ Plate Het. - Homogeneous } & \multicolumn{5}{|c|}{ Plate Het. - PIn Het. (Wh1te B.C.) } \\
\hline & Flux & Resonance & Net & Flux & Resonance & Composition & & Net \\
\hline${ }^{23 e} \mathrm{U}$ oxide & -15.5 & 63.2 & 47.7 & $18.6(-24.1) *$ & 73.0 & $4.6(3.8)^{+}$ & & 96.2 \\
\hline $238 v$ =ecel & 46.3 & 72.6 & 118.9 & & & & & \\
\hline${ }^{239} \mathrm{Pu}$ & 62.3 & -29.5 & 32.8 & $51.3(5.2)$ & -28.0 & $0.7(0.7)$ & & 24.0 \\
\hline${ }^{240} \mathrm{Pu}$ & 14.0 & 5.5 & 19.5 & $13.8(6.9)$ & 4.4 & $-0.5(-0.5)$ & & 17.7 \\
\hline${ }^{241} \mathrm{Pu}$. & -1.1 & -0.1 & -1.2 & $-1.2(-1.4)$ & & $-22.1(-20.7)$ & & -23.3 \\
\hline 241 is & - & & - & - & & $16.5(15.3)$ & & 16.5 \\
\hline${ }^{242} \mathrm{Pu}$ & 0.3 & & 0.3 & $0.2(0.2)$ & & $0.1(0.1)$ & & 0.3 \\
\hline${ }^{235} v$ & -0.2 & & -0.2 & $-0.1(-0.2)$ & & $-1.8(-1.7)$ & & -1.9 \\
\hline נ. & 2.7 & & 2.7 & $1.1(-2.2)$ & & $-0.3(-0.3)$ & & 0.8 \\
\hline$\dot{\imath}$ & 2.5 & & 2.5 & $4: 9(15.2)$ & & $-0.8(-0.9)$ & & 4.1 \\
\hline 5 & -0.7 & & -0.7 & $-0.9(-8.0)$ & & & & \\
\hline Cr & 0.8 & & 0.8 & $-0.2(-1.9)$ & & $29.4(23.5)$ & & 29.2 \\
\hline si & 0.6 & & 0.6 & $0.3(-1.2)$ & $\ldots$ & $15.1(15.5)$ & & 15.4 \\
\hline too & 1.1 & & 1.1 & $.1 .4(1.5)$ & & $-1.5(-1.3)$ & & -0.1 \\
\hline s. & & & & $-0.7(-0.8)$ & & $4.4(2.7)$ & & 3.7 \\
\hline Al, S1, Cu & & & & $-0.1(-0.1)$ & & $0.1(0.1)$ & & 0.0 \\
\hline${ }^{238} \mathrm{u}$ slkt. & & . & & $-5.1(-4.3)$ & & & & -5.1 \\
\hline 235 i Blkt. & & & & $1.1(1.0)$ & & · & & 1.1 \\
\hline $\mathrm{N}_{2}+0 \mathrm{Blkt}$. & & & & $-1.4(-1.5)$ & & . & · & -1.4 \\
\hline Fe. N1, Cr Blkt. & & & & $-3.5(-3.3)$ & & & & -3.5 \\
\hline $\begin{array}{l}\text { Net Colculation } \\
\text { (percusbotion Theory) }\end{array}$ & 113.1 & 111.7 & 224.8 & $88.4(-10.9) *$ & 49.4 & $16.2(10.5)^{+}$ & $!$ & 153.0 \\
\hline $\begin{array}{l}\text { Calculacion } \\
\text { (Direct Elgeavalue) }\end{array}$ & & & & & & & & $140(36)$ * \\
\hline Expericene & & & & 67. & 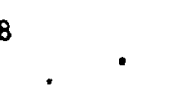 & $8.43 \pm 5.65$ & 1 & $76.1 \pm 1.6$ \\
\hline
\end{tabular}

* Values babod on roflective boundary conditions for transport theory cell calculations. 


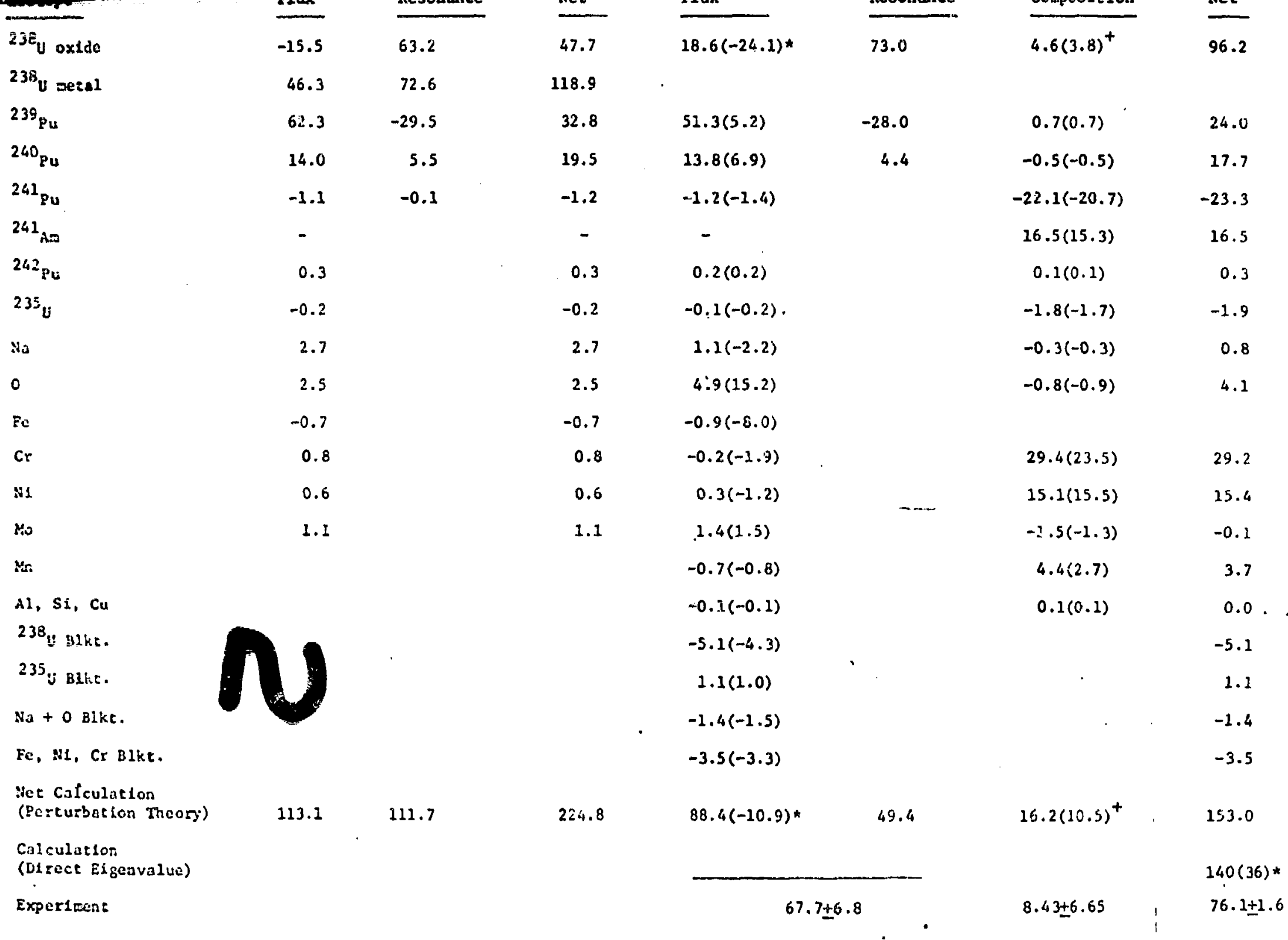

* Vajues based on reflectlve bouidary condltiong for cransport theory cell calculatlons.

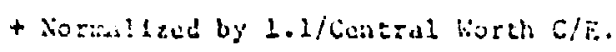


TABLE IL. PLATE AND PIN HETEROGENËTT CALCULATLONS

\begin{tabular}{|c|c|c|c|c|}
\hline & & \multicolumn{3}{|c|}{ CALCULATION } \\
\hline Quanctey & Experiment & W-ARD & $\begin{array}{l}\text { NVL } \\
\text { Idaiso }\end{array}$ & $\begin{array}{l}\text { ANL } \\
\text { ChIcago }\end{array}$ \\
\hline
\end{tabular}

Calculated Total Core Plate $\quad \therefore$

Heteroganetty (\%Ak)

ZPPR-2

Flux

Resonance

ines

$2 p ?-6-7$

Fiux

Resonance

Net

Plate-pin $4 k(1 h)$

ZPRR-2

Flux

Kesonance

Net

2PR-6-7

Net

$\begin{array}{ll}1.00 & 0.9 \\ 0.63 & 0.3 \\ 1.63 & 1.2(1.6) \star \star\end{array}$

1.11

0.24

$1.35(1.66) * \hbar$

* Expected ratlo fcr $\Delta k$ (2PPR-2)/Ak (ZPR-6-7) is approximataly 2.1 .

+ Reflectlve boundary conditlons for pin cell.

$38.4(-10.9)+$

49.4

$137.8(39.5)+\quad 82.6$

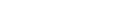

$52.3 \pm 3.4$
50.9

* AVI results using ENDF/B-III dato and SDX crost section averaglng. 


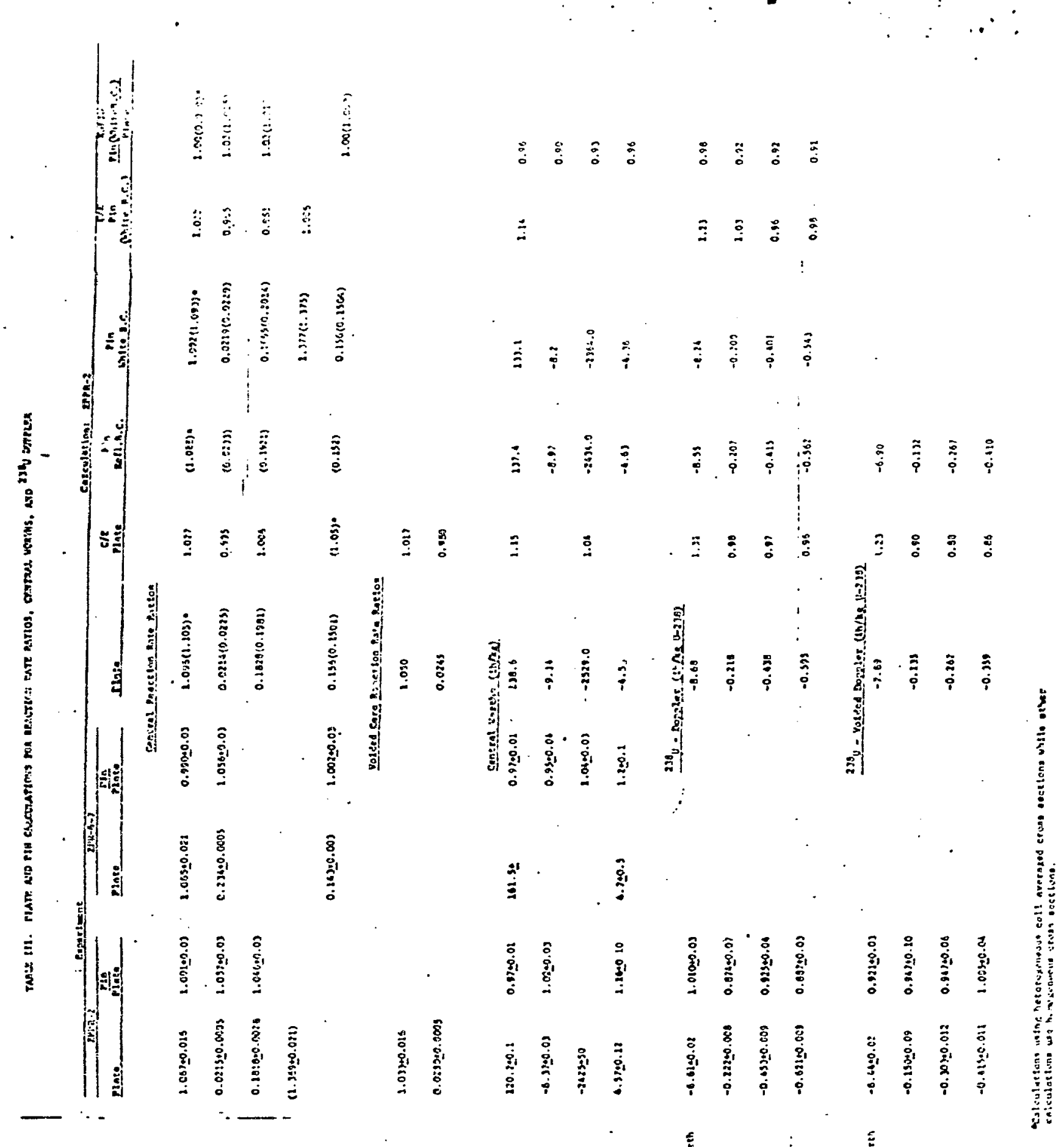

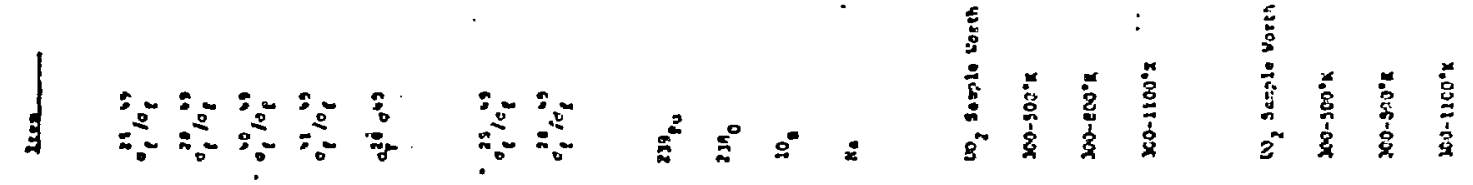




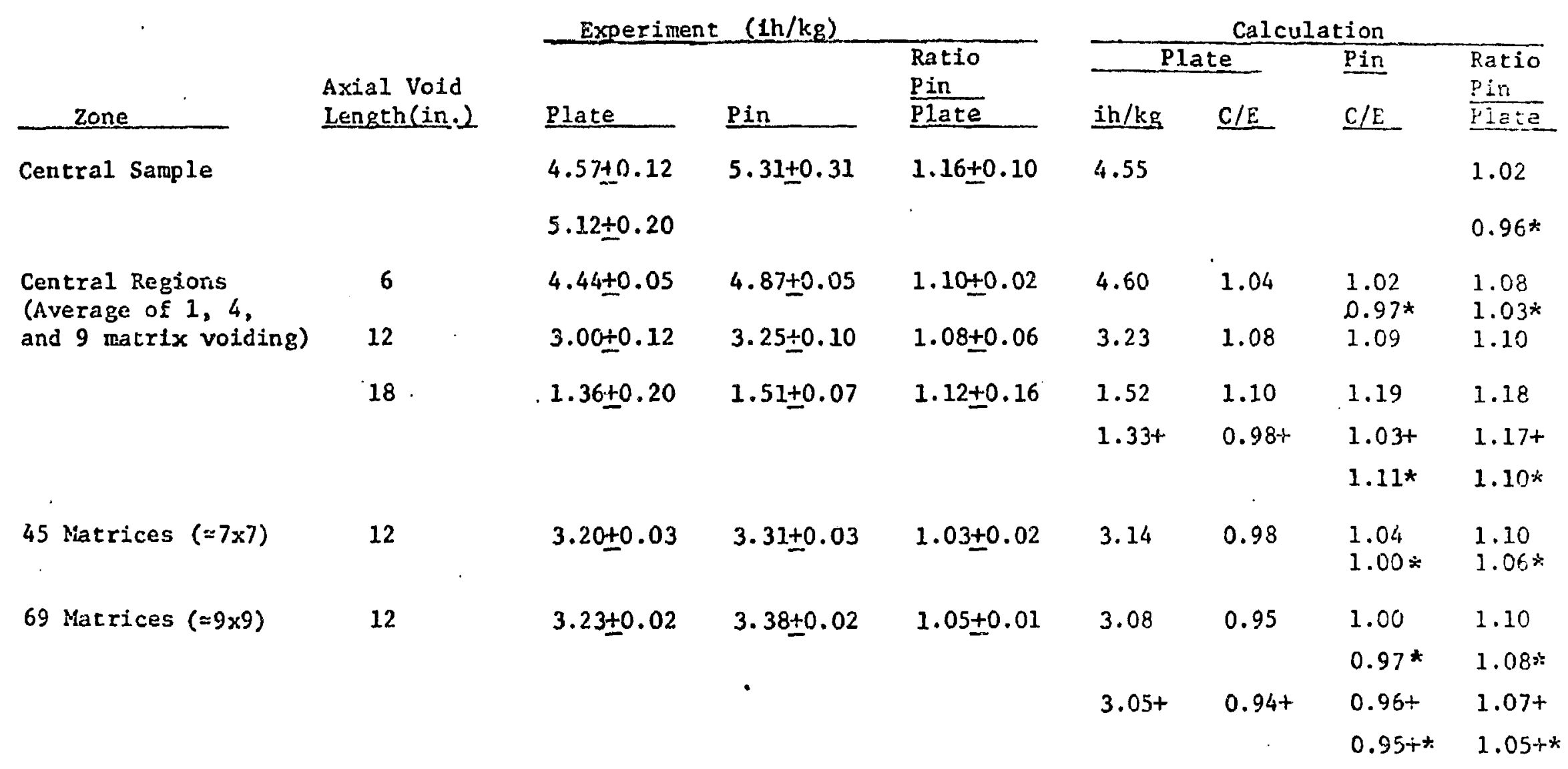

* Calculations using "white" boundary condition in transport theory cell calculations.

+ Iirect elgenvalue difference calculation. 
Table V. Perturbat1on theory Components for Sodium Volding

Components of Sodiun Volding ( $1 \mathrm{~h} / \mathrm{kg}$ )

\begin{tabular}{|c|c|c|c|c|c|c|c|c|}
\hline $\begin{array}{l}\text { Cross Section } \\
\text { Change }\end{array}$ & $\begin{array}{l}\text { Flux } \\
\text { Solution }\end{array}$ & Fission & Abs. & Nod. & $\begin{array}{l}\text { Radial } \\
\text { Leakage }\end{array}$ & $\begin{array}{l}\text { Axial } \\
\text { Leaknge }\end{array}$ & $\begin{array}{l}\text { Net Calc. } \\
(1 \mathrm{~h} / \mathrm{kg})\end{array}$ & Exper1ment \\
\hline \multicolumn{9}{|c|}{ Central Marr1x -6" Axial Vold Length } \\
\hline$d z^{\cot a}$ & plate & -0.80 & 1.85 & 3.88 & 0.00 & -0.31 & $4.62(4.59) *$ & $4.44 \pm 0.05$ \\
\hline$\delta I^{\mathrm{Na}}$ & $\cdot n$ & & 0.78 & 3.52 & & -0.30 & 4.00 & \\
\hline $5 \Sigma^{2 \theta}(F \perp u x)$ & $"$ & -0.13 & -0.04 & 0.05 & & & -0.17 & \\
\hline$c \tau^{49}$ (FIux) & $"$ & -0.40 & 0.02 & 0.02 & & & -0.36 & \\
\hline$S^{28}(\operatorname{Res})$ & $"$ & & 0.85 & 0.01 & · & $\cdot$ & 0.86 & \\
\hline$o t^{49}$ (Res.) & " & -0.19 & 0.14 & & & & -0.05 & \\
\hline $55^{\operatorname{core}}$ & Pin-Re 11. & -0.04 & 1.40 & 3.90 & 0.00 & -0.30 & $4.96(4.93) *$ & $4.87 \pm 0.05$ \\
\hline$\varepsilon E^{N_{a}}$ & $"$ & & 0.77 & 3.54 & . & -0.29 & 4.02 & \\
\hline$S E^{23}(E \perp \cup x)$ & $"$ & -0.08 & -0.11 & 0.04 & & & -0.15 & \\
\hline $3 x^{-5}(\operatorname{siux})$ & $"$ & 0.23 & -0.13 & & & & 0.10 & \\
\hline$\delta z^{2 S}(\operatorname{Res})$ & $"$ & & 0.64 & 0.01 & & & 0.65 & \\
\hline $3 n^{49}(\operatorname{ses})$ & $"$ & -0.28 & 0.13 & & & & -0.05 & \\
\hline $\operatorname{sic} \cos$ & $P \ln -3 r n l t e$ & -0.21 & 1.52 & 3.74 & 0.00 & -0.30 & $4.75(4.72) \star$ & $4.87 \pm 0.05$ \\
\hline 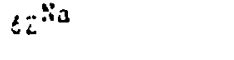 & $"$ & & 0.75 & 3.40 & & -0.29 & 3.86 & \\
\hline
\end{tabular}

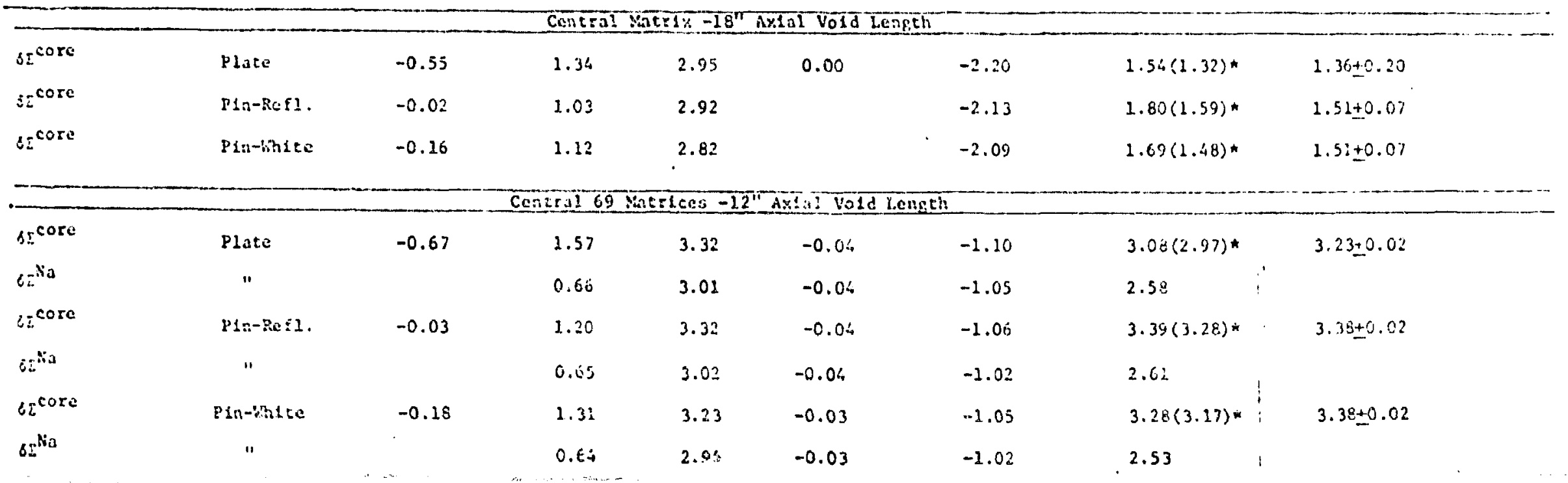




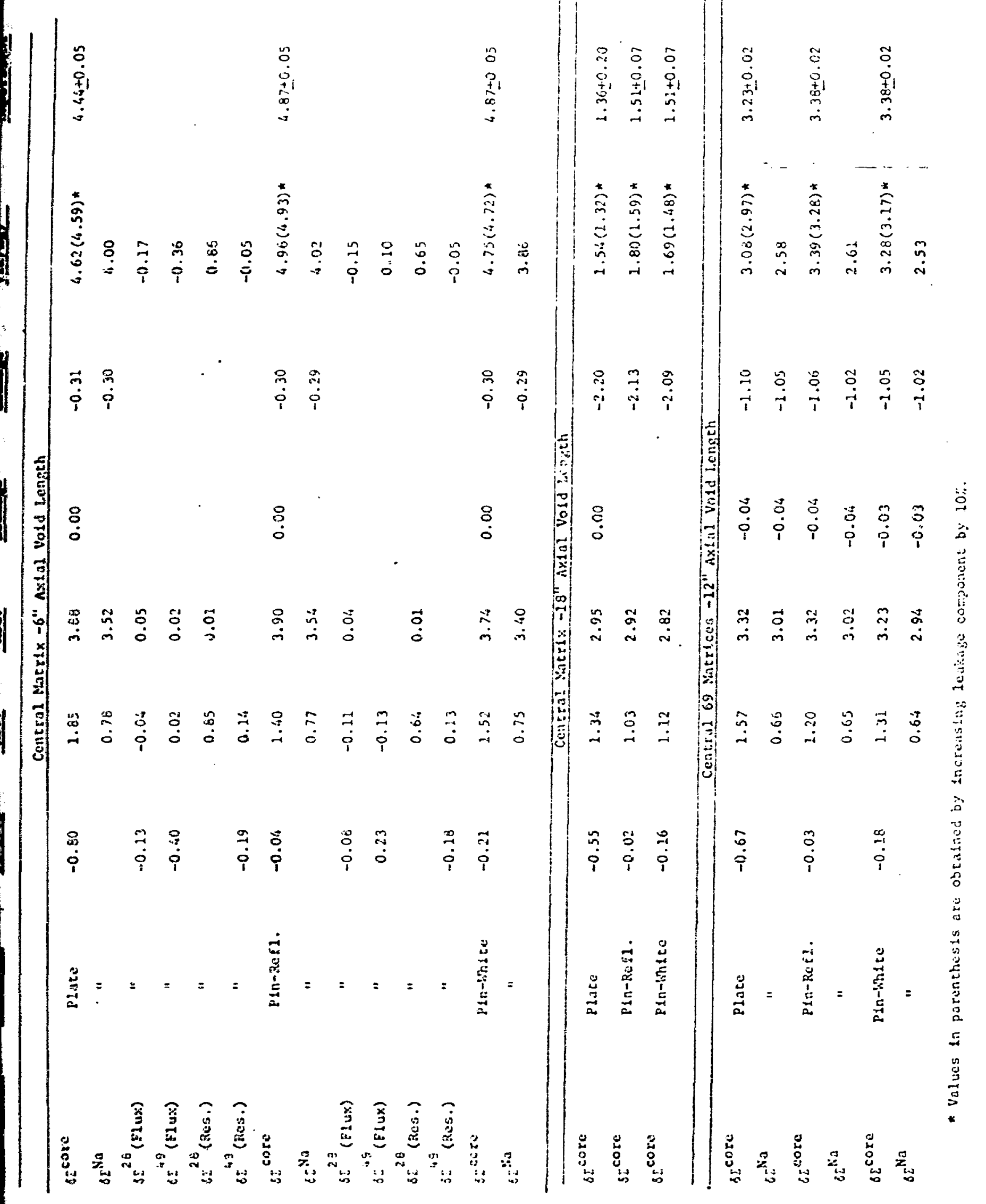




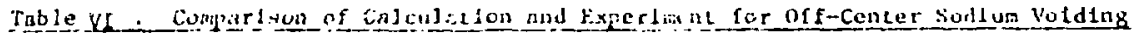

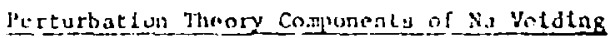

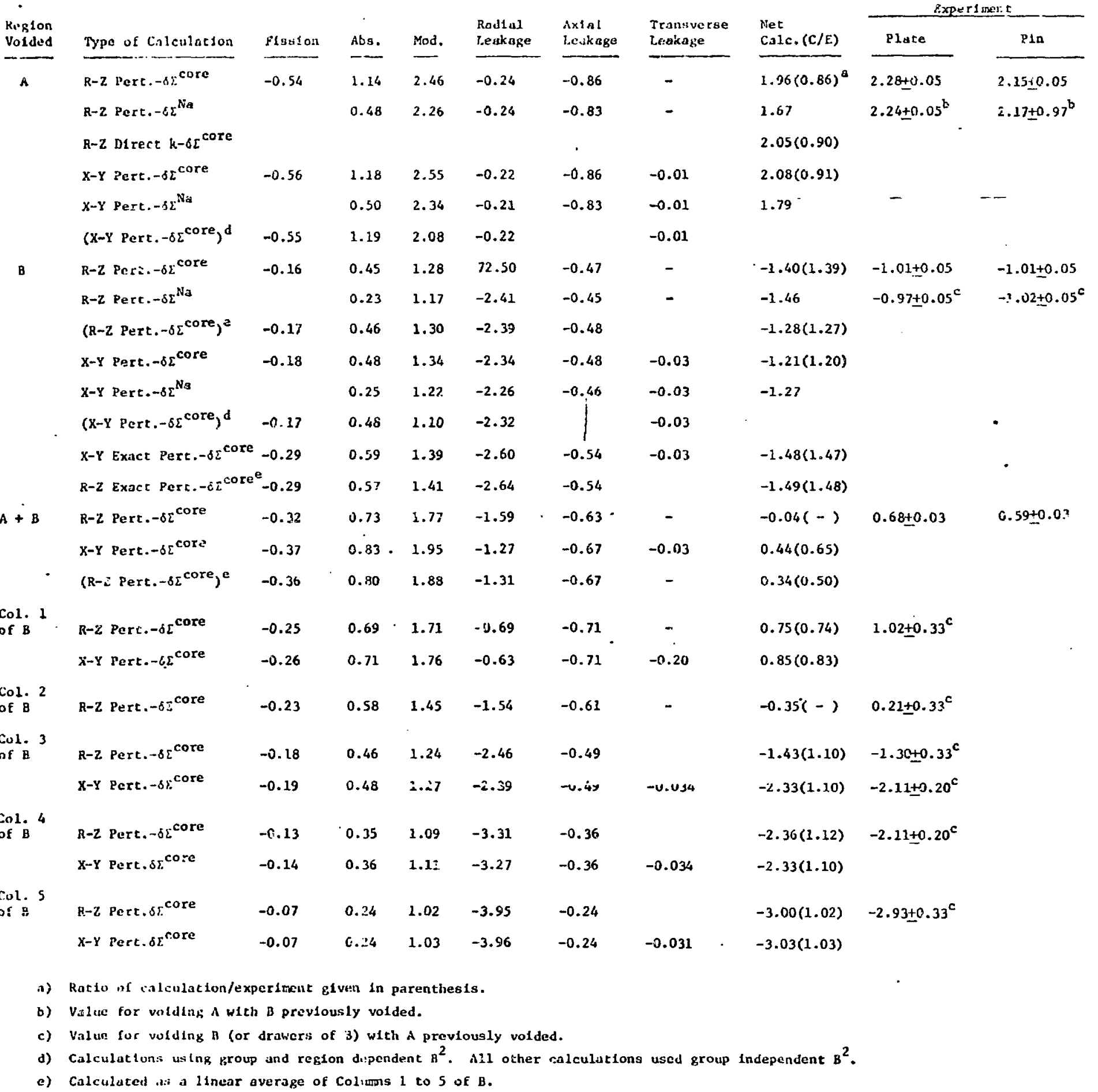




\begin{tabular}{|c|c|c|c|c|c|c|c|c|}
\hline \multirow[b]{3}{*}{ Yeastivenent } & \multirow{2}{*}{\multicolumn{2}{|c|}{ Expertment }} & \multirow{2}{*}{\multicolumn{4}{|c|}{ 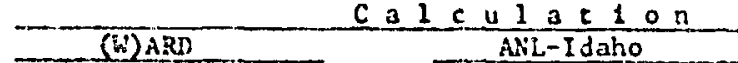 }} & \multirow{2}{*}{\multicolumn{2}{|c|}{ ANL-ChIcazo }} \\
\hline & & & & & & & & \\
\hline & \multirow{2}{*}{$\frac{\text { Pizie }}{67.7 \pm 6.8}$} & $\frac{\operatorname{Pin}}{\operatorname{pisec}}$ & $\begin{array}{l}\text { PLata } \\
\mathrm{C} / \mathrm{E}\end{array}$ & $\frac{\text { Pla }}{\text { Plate }}$ & \multirow{2}{*}{$\begin{array}{l}\text { Pate } \\
\text { C/E } \\
1.22\end{array}$} & $\frac{\text { pln }}{\text { Place }}$ & $\begin{array}{l}\text { Plate } \\
\mathrm{C} / \mathrm{E} \\
\end{array}$ & $\frac{p \overline{p n}}{\text { pintite }}$ \\
\hline Plate vs. Pln ak(in) & & & 2.04 & & & & & \\
\hline . & $52.3 \pm 3.4 *$ & & & & & & $0.97 \star^{\circ}$ & \\
\hline \multicolumn{9}{|l|}{ Sodl godding $(i h / k g)$} \\
\hline $69 \operatorname{sintrtces}$ & $3.23 \pm 0.02$ & $1.05 \pm 0.01$ & 0.9 .4 & 2.05 & 0.78 & 1.06 & & \\
\hline $1=\operatorname{mat} \operatorname{rix}^{k}$ & $6.70 \pm 0.2$ & $1.01 \pm 0.04$ & & & & & $1.03 *$ & $1.05 *$ \\
\hline $9 \operatorname{mat} r i c e s^{*}$ & $6.94 \pm 0.6$ & $0.92 \pm 0.1 i$ & & & & & $0.95 \star$ & $1.06 *$ \\
\hline \multicolumn{9}{|l|}{$238 \mathrm{li}$ bojpler $(\mathrm{H} / \mathrm{k} / \mathrm{k})$} \\
\hline $300-1100^{c}:$ & $-0.621+0.009$ & $0.837 \pm 0.03$ & 0.96 & 0.91 & 1.02 & 0.89 & & \\
\hline \multicolumn{9}{|l|}{$\begin{array}{l}\text { Centeal Reaction } \\
\text { Rate Hates }\end{array}$} \\
\hline $8 \% \frac{8}{8}$ & $2.067 \div 0.016$ & $1.001 \pm 0.03$ & 1.03 & 2.00 & 1.09 & 0.99 & & \\
\hline $03 / 0 \%$ & $0.0215 \pm 0.0005$ & $2.057 \pm 0.03$ & 1.00 & 1.02 & 1.02 & 1.03 & & \\
\hline $0 \% 2 / 10.9$ & $0.1818 \pm 0.003$ & $1.046 \pm 0.03$ & 1.01 & 2.02 & 1.02 & 1.03 & & \\
\hline 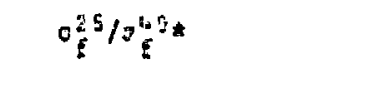 & $1.065 \pm 0.02:$ & $0.990+0.03$ & & & & & $1.08 *$ & i.00* \\
\hline$e^{25} / \sigma^{2 * * *}$ & $0.0334+0.0005$ & $1.056+0.03$ & & & & & $0.99 \star$ & $1.02 *$ \\
\hline $\mathrm{O}_{Y}^{20} \mathrm{jo}_{\tilde{E}}$ & $0.14 \pm \pm 0.003$ & $1.002 \pm 0.03$ & & & & & $1.15 *$ & $1.00 *$ \\
\hline Ceqrini Bortho (Hh/kg) & & & & & & & $!$ & \\
\hline $23 \mathrm{spu}_{\mathrm{Hu}}$ & $130.2+0.1$ & $0.974 \pm 0.01$ & 2.15 & 0.96 & 1.14 & 0.98 & & \\
\hline${ }^{239} \mathrm{fu}^{\mathrm{u}}$ & $15: .5 \pm 0.9$ & $0.975 \pm 0.01$ & & & & & $i^{1.53 n}$ & $0.96 \star$ \\
\hline
\end{tabular}




\section{REFERENCES}

1. P. I. Amundson, et. al.. "Central Zone Plate/Rod Heterogeneity Measurements in the Demonstration Plant Benchmark Critical" ANS Transactions, Vol. 15, No. 1 (June, 1972).

2. A. 01son, R. A. Vosburgh, F. J. Forrester, ANL-7887, p. 7.9 (1971).

3. R. Palmer, private communication.

4. B. A. Zolotar, M. Salvatores, ANL-RDP-2, p. 7.23 (1972).

5. B. A. Zolotar, private communication.

6. R. W. Hardie, W. W. Little, Jr., "loX: A One-Dimensional Diffusion Code for Generating Effective Nuclear Cross Sections", BNWL-954 (1969).

7. T. A. Pitterle, N. C. Paik, "Analysis of ZPPR-2 Plate Measurements; WARD report in publication.

8. T. A. Pitterie, N. C. Paik, C. Durston, "Evaluation and Integral Testing of Modifications to ENDF/B Version II Data", WARO-4210T4-1 (1971).

9. "Revised WANL ANISN Program User's Manual", WAHL-TMI-1967, Apri\} 1969.

10. P. T. Choong: R. D. Schamberger, "Sijcing Technjque for Co:bision Probability Calculations in Cylindrical Geonetry", ANS Transactions, Vol. 15, No. 1 (June, 1972).

11. B. J. Toppe 1, A. L. Rago, D. M. O'Shea, $M C^{2}$, A Code to Calculate Multigroup Cross Sections, ANL-7318 (1967).

12. F. L. Fillmore, B. D. Fenten, "The CALHET Heterogeneous Perturbation Theory Code and Applications to $Z$ PR-3-48", AI-67-9I (1967).

13. R. J. Brissenden, "A Formula for the Escape Probability of a Rod in a Uniform Lattice", AEEW-R.282 (1963). 
This possible explanation appears to be worth more careful study due to the potential impact of such a probiem. Colin Durston of WARD has suggested (private communication) the possibility that different diffusion coefficients (or transport cross sections) may be required parallel and transverse to the plates such as frequently used for thermal reactor applications. The current theory on this problem seem; to be qualitatively consistent with the above leakage speculation.

\section{Comparisons of Independert Plate versus Pin Heterogeneity Calculations}

In addition to the present calculations, the plate versus pin reactivity effects have been calculated for ZPPR-2 by ANL.-Idaho [1] and for ZPR-6-7 by ANL-Chicago [4]. Results of these calculations are given in Table II and include the results of total core plate heterogeneity (plate versus homogeneous) calculations. The ANL calculations of 82.6 in for the ZPPR-2 plate vs. pin reactivity effect differs significantly from the present authors' result of 137.8 ih. About hailf of this difference may be attributable to the plate heterogeneity differences of $1.2 \% \Delta \mathrm{k}$ by ANL and $1.63 \% \Delta k$ by WARD. ANL's latest calculation of $1.6 \% \Delta \mathrm{K}$. for the ZPPR-2 plate heterogeneity is more consistent with the WARD value. Recalculation of the plate vs. pin effect is currently underway at ANL and more detailed comparisons will be possible when these calculations are completed.

The ANL-Chicago calculation of 50.9 in for ZPR-6-7 is in significantly better agreement with exferiment than the $2 P P R-2$ calculations. This improved agreement witii experiment for ZPR-6-7 caiculations is consistent with expectations based on the previous discussions although the ANL C/E value for ZPPR- 2 is notably better than for the WARD caiculations. 